\title{
Syringomyelia as cause of Charcot's arthropathy: a case report
}

Fernanda Tavares de Melo Cavalcanti (HULW-UFPB, João Pessoa, PB, Brasil), Sandra Rejane Cabral Batista (HULW-UFPB, João Pessoa, PB, Brasil), Ana Karla Guedes de Melo (UFPB - HULW, João Pessoa, PB, Brasil), Alessandra de Sousa Braz (HULW-UFPB, João Pessoa, PB, Brasil), Anna Luísa Marinho de Andrade (HULW-UFPB, João Pessoa, PB, Brasil), Eutília Andrade Medeiros Freire (HULW-UFPB, João Pessoa, PB, Brasil)

\section{BACKGROUND}

Charcot's arthropathy is a degenerative, progressive and painless joint disease that occurs in patients with sensory neuropathies. It mainly affects weight bearing joints, such as knees and ankles, but can also affect upper limbs. The main causes are diabetes mellitus, leprosy, alcoholism and tertiary syphilis, but may occur less frequently due to multiple sclerosis, amyloidosis, tumors, spinal cord trauma, among others. Its pathogenesis is controversial, although decreased sensitivity, excessive joint use and repetitive trauma are considered predisposing factors.

\section{CASE REPORT}

Male patient, 50 years old, hypertensive, retired farmer, was admitted complaining of pain and edema in the proximal interphalangeal right $(R)$ hand 10 years ago and R elbow increased volume for 3 months. He also reported that in course of these 10 years, he evolved with flexor deformities of quirodactyls and reduced $\mathrm{R}$ palmar grip strength. He denied smoking, alcoholism, diabetes mellitus or history of trauma. At the musculoskeletal examination, the patient had $\mathrm{R}$ hand in claw deformity, arthritis of $\mathrm{R}$ elbow with bulky effusion and joint dislocation and little pain at palpation. Neurological examination: muscular strength I degree in the extensor muscles of the R hand, scissor gait, tactile hypoesthesia in D lower limb, spasticity grade 2 to 3 in adductor muscles of thighs. Arthrocentesis was performed and synovial fluid was with sero-hematic appearance, whose laboratory analysis ruled out septic arthritis and / or neoplasias. Lymph baciloscopy was negative for leprosy and negative Venereal Disease Research Laboratory (VDRL). Tests of fasting glycemia and glycated hemoglobin within the parameters of normality. Computed tomography of the $\mathrm{R}$ elbow showed a marked articular dislocation with significant erosion of distal humerus cortex, head of the radius and, above all, proximal portion of ulna, associated with the periosteal reaction, besides an important joint effusion, signs of peripheral enhancement and the presence of bone fragments within the joint, suggesting Charcot's arthropathy. Spine magnetic resonance imaging of the spine revealed syringomyelia from $\mathrm{C} 7$ to $\mathrm{T} 7$, measuring about $12.7 \mathrm{~cm}$ in its longitudinal length.

\section{CONCLUSION}

This case shows an unusual association of Charcot arthropathy secondary to syringomyelia at the elbow joint. The authors draw attention to the possibility of syringomyelia among the differential diagnoses of Charcot arthropathy, especially with associated sensorineural changes, making possible an early diagnosis and targeted tracking. 